\title{
Immunoglobulin Constant Region
}

National Cancer Institute

\section{Source}

National Cancer Institute. Immunoglobulin Constant Region. NCI Thesaurus. Code C13242.

The portion of an antibody that is invariant within a class of immunoglobulins. It is comprised of the carboxyl terminal half of both light chains and at least three quarters of each heavy chain starting from the carboxyl terminus and excludes the variable regions of the heavy and light chains. 